\title{
An Anthropological Approach to Therapeutic Strategies for Ethnopharmacology: The case of southwestern Madagascar
}

\section{Research}

\author{
Gabriel Lefèvre
}

\begin{abstract}
Ethnopharmacological investigations typically assume that most remedies of traditional medicine reflect empirical knowledge of the pharmacological properties of plants, although anthropologists generally deny this. Traditional medicine, they claim, mainly obeys social constraints rather than biological ones. Three ethnopharmacological approaches to traditional medicine can be distinguished, corresponding to three operational views of traditional medicine:

1. A selection of pharmacologically interesting plants; the plants used in traditional medicine against a particular illness were selected by the population precisely because they were effective against it.

2. A pre-selection of pharmacologically interesting plants; the plants can have a use in pharmacy even though the latter may not correspond to their local use.

3. An anti-selection of pharmacologically interesting plants; the plants have been identified as being toxic.

I argue that an anthropological study of therapeutic practices is needed to evaluate whether these practices are likely to reflect empirical knowledge, and if so, which kind of knowledge. The latter point is illustrated with examples drawn from research in southwestern Madagascar. Given a particular therapeutic practice, some ethnopharmacological approaches will be more relevant than others. I conclude that ethnopharmacology should rely on an anthropology of therapeutic practices more often that it typically does.
\end{abstract}

\section{Famintinana}

Betsaka ny fanadihadiana efa natao momba ny fanafody fampiasan'ny foko izao sy izao (na eto Madagasikara, na any amin'ny firenena hafa any an-dafy) mba itsaboana ny aretina araka ny fomba nentim-paharazana ananany. Ireny fanadihadiana ireny no ataon'ny mpahalala hoe ethnopharmacology.

Anisan'ny nahavariana ny mpikaroka niditra amin'io resaka ethnopharmacology io ny antony mety nahatonga ny olombelona nifidy ny fanafody maro karazany izay tokony hampiasaina hiadiana amin'ny aretina. Saika manana ny asany daholo amin'ny fitsaboana ny aretina ny hazo sy ny karazan'ny zavamaniry rehetra. Nefa, fomba ahoana, hoy ianareo, no nahafantaran'ireny ombiasy sy mpisikidy ary reninjaza ireny fa fanafody mahasitrana ny aretina izao sy izao ity hazo anankiray ity ? Kanefa itsy hazo karazany hafa itsy, tsy azo ampiasaina amin'izany velively ? Nandova fahalalana tamin'ny ntaolo izy ireny. Nefa taiza no nahafantaran'ny ntaolo ny fampiasana ny fanafody tamin'ny voalohany?

Amin'ny ankapobeny, ny mpikaroka nandinika ny ethnopharmacology dia saika nino fa fahaizana vokatry ny fanandramana natao no nahafahan'ny ombiasy nifidy ny zavamaniry hampiasainy. Naverina matetika hatr'izay ela izay ny fanandramana, hono, ary izay no nahafantaran'ny

\section{Correspondence}

Gabriel Lefèvre, Département systématique et évolution, USM 602 Taxonomie et Collections, Herbier National - plantes vasculaires, Muséum National d'Histoire Naturelle, 57 rue Cuvier, C.P.39 75231 Paris cedex 05, FRANCE.

lefevreg@yahoo.com

Ethnobotany Research \& Applications 6:029-034 (2008) 
ntaolo tsy misy fisalasalana fa ity hazo ity no fanafody, fa tsy hazo hafa.

Izay ny hevitry ny mpanao ethnopharmacology. Misy anefa mpandinika taranja hafa, izay mifanohitra amin'izay ny heviny : dia ny mpikaroka ny rafi-piaraha-monina (social anthropology). Raha araka ny hevitr'ireto farany, tsy ny tena asany amin'ny maha zava-boary azy no nifidianana ny zavamaniry natao fanafody. Tsy dia nahay an'izay loatra manko ny ntaolo, fa antony avy amin'ny takin'ny didin'ny fiaraha-monina no narahany rehefa nifidy hazo na ahitra izy itsaboana ny marary.

Noho izany, raha ho an'ireo mpanao ethnopharmacology, telo karazany ny fomba azo itsarana ny asa fandinihana nataon'ny ntaolo nifidy ny zavamaniry ampiasainy ho fanafody :

1. Ao ny mieritreritra fa ny tena asany fanasitranana no nifidianana azy ; matoa nampiasain'ny ombiasy ny zavamaniry, dia hitany sy fantany fa maharesy ny aretina izy ; azo atao hoe safidy tsotra izao ny fomba nahazoana azy.

2. Ao ny mieritreritra fa hitan'ny ntaolo ihany ny herin'ilay zavamaniry, nefa tsy fantany loatra izay aretina mety ho sitraniny ; mbola azon'ny fitsaboana ara-tsiansa ampiasiana ilay zavamaniry, fa mety amina aretina hafa ; azo atao hoe safidy mialoha ny fomba nahazoana azy.

3. Ao ny mieritreritra fa ny zavamaniry misy poizina mahafaty no hitan'ny mpahay zavatra tamin'ny voalohany, ary noheveriny fa matoa mahery mahafaty ireny dia tsy manimba fotsiny fa mety mahasoa koa mahafaty ny aretina sasany ; safidy amin'ny mifanohitra no azo atao anaran'izany.

Moa ve ahitana karazam-pahaizana miompana amin'ny fanandramana (na empirical knowledge) ny fitsaboana fanaon'ny firenena tsirairay eran'izao tontolo izao ? Fomba fanadihadiana ataon'ny mpikaroka eny an-toerana sy manaraka ny tena fiainan'ny olona andavan'andro no ahazoana mamaly an'izany.

Mba hazava ny resaka, dia tsy maintsy idirana amin'ny antsipiriany ny fahaizana ananan'ny mpitsabo. Ohatra vitsivitsy avy amin'ny fikarohana nataoko no aseho amin'ity lahatsoratra ity. Avy amin'ny faritany atsimo andrefan'i Madagasikara daholo ny ohatra noraisina.

\section{Résumé}

Les enquêtes ethnopharmacologiques partent généralement du principe que la majorité des remèdes de la médecine traditionnelle reflètent un savoir empirique sur les propriétés pharmacologiques des plantes, idée qui n'est pas généralement partagée par les anthropologues. Ces derniers affirment en effet que la médecine traditionnelle obéit à des contraintes sociales plutôt que biologiques.
Trois approches ethnopharmacologiques de la médecine traditionnelle peuvent être distinguées, correspondant à trois vues opératoires des pratiques thérapeutiques traditionnelles:

1. Une sélection des plantes pharmacologiquement intéressantes; les plantes utilisées dans la médecine traditionnelle contre une maladie particulière ont été sélectionnées par la population précisément parce qu'elles sont efficaces contre elle

2. Une pré-sélection des plantes pharmacologiquement intéressantes ; les plantes peuvent détenir une propriété pharmaceutique même si cette dernière ne correspond pas à l'usage local

3. Une anti-sélection des plantes pharmacologiquement intéressantes; les plantes ont été identifiées comme toxiques.

Je défends qu'une étude anthropologique des pratiques thérapeutiques est nécessaire pour évaluer si ces pratiques sont susceptibles de refléter un savoir empirique, et si c'est le cas, quel type de savoir. Le dernier point est illustré avec des exemples tirés de recherches effectuées dans le sud-ouest de Madagascar. En fonction de la pratique thérapeutique envisagée, certaines approches ethnopharmacologiques seront plus appropriées que d'autres. Je conclus que l'ethnopharmacologie devrait reposer plus souvent sur une anthropologie des stratégies thérapeutiques.

\section{Introduction}

In Madagascar, ethnopharmacological investigations typically assume that most remedies of traditional medicine reflect an accumulated empirical knowledge of pharmacological properties of plants (Boiteau et al. 1999, Debray et al. 1971). Other researchers do not share this conviction. According to them, these therapeutics are aimed at diseases of the society and the family, not diseases of the body. They follow a social logic, as opposed to biological logic. Consequently, these practices are not necessarily effective because of the pharmacological properties of the plants (Ramamonjisoa 1994). Both positions could draw arguments from the study of the traditional practices of Madagascar. On the one hand, traditional medicine includes magical practices. In some instances, diagnoses are established through divination by the sikily, sikidy, in which one interprets geomantic figures made by seedpatterns, sometimes in combination with astrology. The resulting readings can prescribe sacrifices and/or the manufacture of remedies, or charms aoly, aody. But even in the latter case, although plants are usually required for making remedies, their role is limited to that of an "additive" (Beaujard 1988). The efficacy of plants would not be due to their pharmacological properties, but to their "magical-religious significiance" (Ramamonjisoa 1994). On the other hand, in rural areas, the majority of people exhibit an extensive knowledge of plants in their daily activities 


\section{Lefèvre - An anthropological approach to therapeutic strategies for ethnopharmacology: the case of southwestern Madagascar}

such as construction, food, hunting or fishing. In particular, widespread remedies such as the use of the guava against dysentery are commonly regarded as effective.

During several ethnobotanical surveys in the Masikoro region in 2002 and 2004, in southwest Madagascar, I met some specialists with a wide range of opinions about the effectiveness of traditional medicinal plants. In my view, three ethnopharmacological approaches should be distinguished (see section I below). The ethnopharmocology of selection assumes that traditional medicinal plants were actually selected for their efficacy against the disease for which they are used. The ethnopharmacology of pre-selection assumes only that traditional medicine makes a pre-selection of potentially active plants - but the plants need not necessarily be efficient against the disease for which they are used. The ethnopharmacology of anti-selection focuses on plants that are excluded as being toxic by traditional medicine. Such plants are more likely to have a pharmacological interest than others.

Now, my main thesis is that, depending on the particular therapeutic strategy associated with a given remedy, some ethnopharmacological approaches will be more relevant than others. Accordingly, ethnopharmacology should rely on anthropological data about therapeutic strategies, more often than it usually does (see section II below).

\section{Ethnopharmacological investigations}

As mentioned above, ethnopharmacological surveys that are carried out today can be seen as belonging to three main types. Some investigations may nevertheless combine these types of approaches.

\section{Ethnopharmacology of selection}

The first type of investigation assumes that the plants used in traditional medicine against a particular illness were selected by the population precisely because they were effective against it. The pharmacologist may thus take these plants to contain an isolable and potentially exploitable compound. This method is inspired by the fact that many substances of interest, such as quinine or artemisine, were discovered this way. These two molecules are extracted from traditionally used plants, and are the basis of antimalarial treatments. The qinghao (Artemisia annua L., Asteraceae) was mentioned as an antipyretic in China as early as $168 \mathrm{BC}$. The powdered bark of quinquina, in particular the red quinquina (Cinchona pubescens Vahl, Rubiaceae), which was first characterized in 1633, was used by the Incas to fight the "third fever" (Sévenet \& Tortora 1994).

\section{Ethnopharmacology of pre-selection}

The second type of investigation assumes that traditional medicine carried out a pre-selection of potentially active plants. These plants can have a use in pharmacy, even though the latter may not correspond to their local use. The Madagascar periwinkle (Catharanthus roseus (L.) G. Don, Apocynaceae) is a good example. Known for its bitterness, this plant is traditionally used for its appetite suppressing effects. It was during a study on diabetes that its antitumoral activity was first noticed (Tyler 1986). More generally, it is noticeable that many plants selected for traditional medicine are either bitter, or contain essential oils. By selecting bitter plants, traditional healers actually identify the plants which contain alkaloids (Fox 1953). In the same way, plants with essential oils contain volatile components which are particularly powerful (Bruneton 1997).

\section{Ethnopharmacology of anti-selection}

The third type of investigation assumes that traditional medicine carries out an anti-selection by excluding plants which are identified as being toxic. The substances which are toxic for humans are indeed active on our physiology, and many remedies used in pharmacy are derived from toxic plants. The study of plants traditionally known to be harmful is thus thought to lead to the discovery of new actives substances. For instance, Digitalis spp. (Scrophulariaceae), known to be very toxic in popular European pharmacopeia, are now used for the synthesis of cardiotonic pharmaceuticals (Bruneton 1997). However, Malagasy traditional healers use toxic plants only on very rare occasions. This has lead ethnopharmacologists to become interested in the so-called mpamoriky or "poisoners", who are said to be experts in toxic plants, and whose alleged activities are criminal. They are sometimes described as a class of specialists, namely traditional healers who turned towards this speciality; or as traditional healers who secretly carry on this activity alongside their normal practices.

\section{Anthropology of therapeutic strategies}

Various therapeutic strategies coexist in the Masikoro region, in sub-arid southwest Madagascar. They can be examined and contrasted with their potential for ethnopharmacological investigation borne in mind.

\section{The Masikoro's holistic view of illness by}

In the Masikoro conception of therapy, membership in the community and respect of lineage values are the means by which disease is prevented. For instance, the term "arety," usually simply translated as "disease," is in fact used by the Masikoro to refer to various things such as any disease of the body, heart or spirit, be it a moral or 
ritual fault, a social conflict or a disease proper. When the social cohesion is disturbed, Masikoro believe that the ancestors may punish the living, in particular by inflicting serious illnesses on them. To be cured, patients must regain the favor of the ancestors (Ramamonjisoa 1994). Natural aspects of the disease, such as its symptoms and the associated cause (insect bite, food, etc.), are regarded as secondary because they are only the means by which the ancestors are punishing the living. In other words, this holistic view distinguishes the natural (biological) cause of the disease from its supernatural origin. However, only certain diseases are believed to have a supernatural origin. Certain types of spiritual healers deal particularly with these diseases. The action of spiritual healers is systemic: it involves rebalancing the social and cosmic order of the patient. By contrast, other diseases are considered to have a merely natural origin. For those, the Masikoro call upon another type of healer - material healers who practice a symptomatic medicine, that is a medicine in which the prescriptions are directly determined by the symptoms observed.

\section{Difficulties of the ethnopharmacology based on spiritual healers}

There are two types of spiritual healers in the Masikoro country: the tromba and the ombiasa. The tromba, a medium, is possessed by a spirit that speaks through him during trances. He is unconscious during the trance, and an assistant reports the prescriptions made by the spirit. The ombiasa, soothsayer and healer, uses techniques of divination and astrology as well as knowledge of plants. His diagnosis is based on elements such as zodiac signs and the patients' day of birth, as well as interpretation of the sikily. He has the capacity to cure, modify the social condition of his patients, and even to deliver reprisals, or preventions, against the malefic wizards. These two types of healers prescribe remedies which consist primarily of a well-defined ritual. Ramisiray (1901) recounted for example a ritual process used in northern Madagascar when the growth of teeth is delayed: "One takes white rice and throws it in a deep ravine; one then takes the young child by the feet and one suspends it above the chasm by calling upon the ancestors, the vazimba, etc.: "Omeo nify $\mathbf{R e}$ ry razana." (Give teeth, oh my ancestors)." These rituals consist primarily of sacrifices and manufacture of charms aoly, ody which generally contain plants.

The main point that should be noted about these practices is that although these healers prescribe remedies containing plants, the choice of these plants is not mainly founded on the examination of the symptoms of the patient. Rather, it is based on the processes of divination, which appear to be random to a rationalist observer such as a doctor or a pharmacologist. Consequently, the ethnopharmacologist would be mistaken to attribute to these healers a symptomatic conception of medicine. This is what happens when one says for instance that "[it] is cer- tainly today, in the populations close to nature, the role of the traditional healer in Melanesia, the wizard or the tradipratician in Africa, the curandero in South America, [... ] to pose a diagnosis, to find the adequate plant and eventually to cure the patient [... ] It is to these keepers of ancestral knowledge that the researcher turns himself today to know 'the secrecy of the plants that cures'." (Sévenet \& Tortora 1994)

For example, one tromba in the Masikoro region says that "the phenomenon of trance is the setting-off of his know-how". An ethnopharmacologist with whom I discussed this interprets this claim in the following way: the trance is a mystification used by the healer in order to get credit about his abilities while masking the true origin of the remedy's efficacy, namely the plants. The investigator thus takes this to be evidence of a hidden symptomatic medicine. But in fact, the "know-how" that the tromba mentions here is rather his ability to detect the supernatural forces that cause the illness.

These facts show that the selection ethnopharmacological approach cannot be applied to these healers' knowledge without misunderstanding, and that its chances of success are weak. The pre-selection approach is not entirely without value, but the difference between the logic that governs the choice of plants in the healer's system and the logic that governs it in the researcher's system suggests that few results are to be expected.

\section{Interest in the ethnopharmacology of material-healers}

Examples of material healers include the karimbola, or a bone setter, who has a recognized technique, and the reninjaza, or a midwife, who knows the plants to be used for taking care of the newborn. For instance, the fontanel of infants is popularly taken to have dysfunctions, and several plants, known to midwives, are used in relation to it. In the same way, the bone setters can effectively heal fractures and distortions by associating techniques of massage with plants used in cataplasms.

This medicine is symptomatic: treatments are adapted to the symptoms. The role of the healer is similar to that of a biomedicine doctor: a given symptom is associated with a given medication. One can thus expect that these practices led to the empirical selection of the relevant active substances. Consequently, an ethnopharmacology of selection can be based on these healers' knowledge.

When the diseases defined by local science are without equivalent in the biomedical nosology, as in the case of the fontanel, one can nevertheless hope that the practices used select active substances. They might be substances that are useful to the baby, for instance. 


\section{Lefèvre - An anthropological approach to therapeutic strategies for ethnopharmacology: the case of southwestern Madagascar}

Ethnopharmacological investigation is therefore more likely to be successful in relation to material healers. Moreover, such an investigation is clearly simpler with material healers than spiritual ones. Whereas with the latter, the same symptom may be treated in a variety of ways, depending of the result of the divination or possession, for the former, each symptom is correlated with one or more plants.

\section{The poisoners}

If there are poisoners (mpamoriky) who know toxic plants, their knowledge can undoubtedly be of use to the investigations of the ethnopharmacologists who believe that the selection and pre-selection approaches are less useful than the anti-selection approach. However, it would be erroneous to ignore the anthropological dimensions of this phenomenon. Initially, certain advisors distinguish between the mpamosavy, who have magic abilities, and the mpamoriky, who are true poisoners and know toxic plants. The category of mpamoriky remains a mystery. The ombiasa are feared because they have the capacity to bewitch as well as to cure, and it is said that some mpamoriky are former ombiasa. Do mpamoriky really exist? Are they (or were they once) ombiasa or other people? And how are they to be found given that the population regards them as criminals?

Most toxic plants are known to everybody, and the antiselective approach can be more easily used in relation to people who simply know the plants well. Besides, the accounts of poisoning about which one more often hears mention of chemical poisons such as battery acid than poisonous plants. Finally, if mpamoriky really exist, it is essential to determine if their practice is of the type used by spiritual healers or by the material healers. In the first case, the anti-selection approach would encounter the same difficulties as the selection and pre-selection approaches encounter with the spiritual healers.

\section{Conclusion}

It is commonly held that the length of time a population has been present in a given place and its appropriation of the local natural resources are correlated. This idea stems from the postulate that sustained interaction with a natural environment results in an improved empirical knowledge of its useful and harmful elements. This idea, however, ignores several anthropological dimensions of human culture. For one, therapeutic practices are typically part of a holistic belief system that might prevent the empirical gathering of knowledge from being effective. This is the case when prescriptions are based on divinations rather than symptoms. Moreover, the history of these practices may reveal that some of their elements do not result from an interaction with the local environment. For instance, the sikily divination by interpretation and astrology was introduced to Madagascar from the Arab-Muslim world at times when undoubtedly a form of medicine based on plants already existed in Madagascar. Finally, therapeutic practices can consist in part of the reproduction of preestablished practices, thereby restraining the experimentation necessary for empirically exploring the properties of the resources. Consequently, ethnopharmacological investigation cannot be done without an anthropological study of therapeutic strategies. In the case of southwestern Madagascar, I argue that the present study would reorient ethnopharmacological investigation towards those I called material healers. Evil figures such as the mpamoriky are also likely to hold the kind of knowledge of plants that is of interest to pharmacologists. An anthropological investigation is still necessary to establish if the mpamoriky really exist, and if so, how one can establish the contact with them.

\section{Acknowledgements}

I wish to thank the people of Toliara and surroundings for information and much assistance.

I also wish to thank Lucile Allorge (Centre National de la Recherche Scientifique, Gif sur Yvette), Claude Allibert (Institut National des Langues et Civilisations Orientales, Paris), Philippe Rasoanaivo (Institut Malgache de Recherche Appliquée Anatananarivo), Noël J. Gueunier (Université Marc Bloch, Strasbourg) under the supervision of whom I conduced this work.

Thanks for their help and advices to Porter P. Lowry II (Missouri Botanical Garden, St Louis), Peter B. Phillipson (Missouri Botanical Garden, St Louis), Barry Ferguson (University of East Anglia, Norwich), Jean Bertin Iréné Ramamonjisoa (Université des Lettres, Toliara), Emmanuel Fauroux (Institut de Recherche et Développement, Paris), Benoit Rasolondratovo (Université des Sciences, Toliara), Jean-Noël Labat (Muséum National d'Histoire Naturelle, Paris), Thomas Haevermans (Muséum National d'Histoire Naturelle, Paris), Narivelo Rajaonarimanana (Institut National des Langues et Civilisations Orientales, Paris) and Clément Sambo (Ecole Normale Supérieure, Toliara).

\section{Literature Cited}

Beaujard, P. 1988. Plantes et médecine traditionnelle dans le Sud-Est de Madagascar. Journal of Ethnopharmacology 23:165-265.

Boiteau, P. , M. Boiteau \& L.Allorge. 1999. Dictionnaire des noms malgaches des végétaux. Alzieu, Grenoble.

Bruneton, J. 1997. Pharmacognosie: Phytochimie, plantes médicinales, Techniques et Documentation. Lavoisier, Paris. 
Debray, M., H. Jacquemin \& R. Razafindrambao 1971, Contribution à l'inventaire des plantes médicinales de Madagascar. Office de la Recherche Scientifique et Technique d'Outre-Mer, Paris.

Fox, R.B. 1953. The Pinatubo Negritos: Their Useful Plants and Material Culture. Philippine Journal of Science 81(3-4):173-414.

Ramamonjisoa, J.B.I. 1994. La maladie et la guérison chez les Masikoro de la région de Tuléar (Sud-Ouest de Madagascar) Diagnostiquer et guérir. (Doctorat en Études
Africaines sous la direction du Professeur Pierre Vérin), Institut National des Langues et Civilisations Orientales, Paris.

Ramisiray, G. 1901. Pratiques et croyances médicales des malgaches. (Doctorat de médecine), A. Maloine, Paris.

Sévenet, T. \& C. Tortora. 1994. Plantes, molécules et médicaments. Nathan, Paris.

Tyler, V.E. 1986. Plants drugs in the twenty-first century. Economic Botany 40:279-288. 